\title{
STUDI NILAI TAMBAH PENGOLAHAN BANDENG DI KECAMATAN PALIBELO KABUPATEN BIMA (KASUS PADA USAHA BANDENG PRESTO)
}

\author{
STUDY OF ADDED VALUE OF MILKFISH PROCESSING \\ AT PALIBELO DISTRICT IN BIMA REGENCY \\ (CASE OF MILKFISH PRESTO)
}

Imam Afandy, Bambang Dipokusumo, dan Dwi Praptomo Sudjatmiko

Program Studi Agribisnis Fakultas Pertanian Universitas Mataram

\begin{abstract}
ABSTRAK
Penelitian ini bertujuan untuk : (1) Mengetahui proses pengolahan bandeng menjadi bandeng presto, (2) Menganalisis nilai tambah yang dihasilkan dari olahan ikan bandeng menjadi bandeng presto, dan (3) Mengetahui kendala usaha rumah tangga pada usaha pengolahan bandeng presto di Kecamatan Palibelo Kabupaten Bima. Metode yang digunakan dalam penelitian ini adalah metode deskriptif, sedangkan pengumpulan data dilakukan dengan teknik wawancara. Hasil penelitian menunjukkan bahwa : (1) Proses pengolahan pada usaha bandeng presto terdiri dari 6 (enam) tahap yaitu pembersihan bahan baku, pembuatan bumbu, pelumuran bumbu, memasak bandeng, pendinginan, dan pengemasan. (2) Nilai tambah untuk bandeng presto adalah Rp 21.219/kg bahan baku dengan rata-rata pendapatan sebesar Rp1.535.424 per daur usaha produksi, Rasio nilai tambah bandeng presto yaitu $42,44 \%$ artinya setiap Rp 100,- nilai produksi akan menghasilkan nilai tambah sebesar Rp 42,44 dan (3) Kendala-kendala yang dihadapi nelayan dalam usaha pengolahan bandeng yaitu kendala bahan baku, pemasaran, dan modal.
\end{abstract}

Kata kunci : bandeng presto, nilai tambah

\section{ABSTRACT}

This study aims to: (1) To know milkfish presto process, (2) to analyze added value generated from milkfish presto processing, and (3) To know the constrains factor for home agro industry to run milkfish presto in Palibelo District, Bima Regency. The method used in this research was descriptive method, while data collection was done by interview technique. The results showed that: (1) The processing of Milkfish Presto consisted of 6 (six) namely were raw material (fresh milkfish) collecting, spice making, seasoning, milkfish cooking, cooking, and packaging. (2) Added value for milkfish presto was IDR. 21,219/kg of fresh milkfish dan IDR. 1.535.424 for one time of processing, and (3) the constraints factors were capital, fresh milkfish dan marketing.

Keywords: Milkfish Presto, added value 


\section{PENDAHULUAN}

Provinsi Nusa Tenggara Barat terdiri dari dua pulau besar yaitu pulau Lombok seluas kurang lebih 4.738,7 $\mathrm{km}^{2}$ dan pulau Sumbawa seluas kurang lebih $15.414,4$ $\mathrm{km}^{2}$. NTB merupakan salah satu daerah produksi perikanan di Indonesia bagian timur dan merupakan daerah yang potensial untuk pengembangan produksi perikanan laut (Dinas Kelautan dan Perikanan NTB, 2014).

Berdasarkan data dari hasil survey Badan Pusat Statistik, Dinas Kelautan dan Perikanan NTB, jumlah hasil produksi dan nilai produksi perikanan laut dari tahun ke tahun mengalami fluktuasi. Pada tahun 2015 jumlah hasil produksi perikanan laut sebesar 1.129.822,85 ton dengan nilai produksi sebesar Rp 3.993.078.064. Sedangkan untuk tahun 2016 jumlah hasil produksi perikanan laut mengalami kenaikan sebesar $1.172 .425,86$ ton per tahun dengan nilai produksi yang juga meningkat yaitu sebesar Rp 4.732.128.678. Kemudian pada tahun 2017 jumlah hasil produksi perikanan laut kembali mengalami kenaikan sebesar $1,199,886.98$ ton dengan nilai produksi Rp 4.895.203.127.

Kecamatan Palibelo Kabupaten Bima merupakan salah satu wilayah di Provinsi Nusa Tenggara Barat (NTB) yang memiliki potensi pengembangan usaha budiadaya tambak yang cukup besar, yaitu budidaya bandeng. Usaha budidaya tambak ikan bandeng merupakan salah satu usaha perikanan yang cukup penting, hal ini disebabkan karena bandeng memiliki kualitas yang cukup bagus. Produksi ikan bandeng di Kecamatan Palibelo Kabupaten Bima pada tahun 2013 sebesar 3.698,22 ton dan pada tahun 2015 mencapai 15.058,2 ton.

Usaha dalam melaksanakan pengolahan dapat dilakukan dengan berbagai macam cara. Misalnya, ikan segar yang baru ditangkap dapat dipertahankan kesegarannya dengan cara didinginkan atau dibekukan, atau dapat pula diolah menjadi produk dengan nilai jual yang lebih tinggi seperti pembuatan presto.

Dengan permasalahan tersebut, maka perlu dilakukan penelitian "Studi Nilai Tambah Pengolahan Bandeng di Kecamatan Palibelo Kabupaten Bima (Kasus Pada Usaha Bandeng Presto)".

Penelitian ini bertujuan untuk : (1) Mengetahui proses pengolahan bandeng menjadi bandeng presto, (2) Menganalisis nilai tambah yang dihasilkan dari olahan ikan bandeng menjadi bandeng presto di Kecematan Palibelo, Kabupaten Bima, dan (3) Mengetahui kendala usaha rumah tangga pada usaha pengolahan bandeng presto.

\section{METODE PENELITIAN}

Metode yang digunakan dalam penelitian ini adalah metode deskriptif, sedangkan pengumpulan data dilakukan dengan teknik wawancara. Penelitian ini dilakukan di Kecamatan Palibelo. Penentuan wilayah penelitian ini yaitu secara purposive samplingdengan pertimbangan bahwa di Kecamatan Palibelo Kabupaten Bima terdapat penduduk yang mengusahakan bandeng presto dalam bentuk usaha rumah tangga.

Jumlah responden ditentukan secara sensus sebanyak 20 orang produsen pengolahan bandeng presto dengan pertimbangan bahwa hanya terdapat 20 pengusaha bandeng presto di Kecamtan Palibelo Kabupaten Bima. 


\section{Analisis StrukturBiaya}

Untuk mengetahui struktur biaya dari usaha pengolahan bandeng presto di Kecamatan Palibelo Kabupaten Bima, yaitu dengan menggunakan rumus sebagai berikut :

$$
\text { TC }=\text { TFC }+ \text { TVC }
$$

Keterangan :

TC : Total Cost (Total biaya)

TFC : Total Fixed Cost ( Total biaya tetap)

TVC : Total Variabel Cost (Total biaya variabel)

\section{Analisis Pendapatan}

Untuk mengetahui besarnya pendapatan yang diterima oleh produsen usaha pengolahan bandeng presto, yaitu dengan menggunakan rumus sebagai berikut :

$$
\boldsymbol{\pi}=\mathbf{T R}-\mathbf{T C} \operatorname{dimana} \mathbf{T R}=\mathbf{P} \times \mathbf{Q}
$$

Keterangan :

$$
\begin{array}{ll}
\pi & =\text { Pendapatan } \\
\text { TR } & =\text { Total penerimaan (Total revenue) } \\
\text { TC } & =\text { Total biaya (Total cost) } \\
\mathrm{P} & =\text { Harga (Price) } \\
\mathrm{Q} & =\text { Jumlah produksi (Quantity) } \\
\text { TFC } & =\text { Total biaya tetap (Total fixed cost) } \\
\text { TVC } & =\text { Total biaya variabel (Total variable cost) }
\end{array}
$$

\section{Analisis Nilai Tambah}

Untuk mengetahui besarnya nilai tambah dan keuntungan yang diperoleh dari usaha pengolahan bandeng presto dapat dihitung melalui data primer yang diperoleh dari responden yang kemudian dianalisis dengan menggunakan "Metode Hayami".

\section{Kendala atau Hambatan}

Untuk mengetahui kendala atau hambatan dalam pengolahan ikan bandeng segar menjadi bandeng presto, maka dilakukan analisis secara deskriptif, yaitu data yang diperoleh dari responden selanjutnya akan dideskripsikan dan diambil kesimpulan.

\section{HASIL DAN PEMBAHASAN}

\section{Struktur Biaya dan Pendapatan}

Struktur biaya pada usaha pengolahan bandeng presto dalam penelitian ini meliputi : (1) Biaya bahan baku; (2) Bahan penolong; (3) Biaya tenaga kerja; (4) Biaya tetap; dan (5) Biaya lain-lain.Adapun rata-rata biaya pada usaha pengolahan bandeng presto di Kecamatan Palibelo berdasarkan produk yang dihasilkan oleh produsen disajikan pada Tabel 1 berikut. 
Tabel 1. Struktur Biaya Pengolahan Bandeng Presto Tahun 2020

\begin{tabular}{|c|c|c|c|}
\hline \multirow{2}{*}{ No. } & \multirow{2}{*}{ Jenis Biaya } & \multicolumn{2}{|c|}{ Bandeng Presto } \\
\hline & & Nilai (Rp) & Persentase $(\%)$ \\
\hline 1. & Biaya Variabel & & \\
\hline & - Bahan Baku & 744.953 & 79,92 \\
\hline & - Bahan Penolong & 72.348 & 7,77 \\
\hline & - Biaya Tenaga Kerja & 109.287 & 11,72 \\
\hline 2 & Biaya Tetap & & \\
\hline & - Penyusutan Alat & 5.488 & 0,59 \\
\hline & Total & 932.076 & 100 \\
\hline
\end{tabular}

Sumber : Data Primer Diolah (2020)

\section{Biaya Variabel}

Biaya variabel adalah biaya yang besar kecilnya dapat mempengaruhi jumlah produksi. Dalam penelitian ini biaya variabel terdiri dari biaya bahan baku, biaya bahan penolong dan biaya tenaga kerja.

Biaya bahan baku.. Dari Tabel 1 bahan baku yang dimaksud dalam penelitian ini adalah bandeng segar. Rata-rata jumlah bahan baku yang digunakan oleh produsen bandeng presto dalam satu kali proses produksi untuk produk bandeng segar adalah $49,66 \mathrm{~kg}$ dengan harga rata-rata $\mathrm{Rp} 15.000 / \mathrm{kg}$, sehingga rata-rata biaya yang dikeluarkan untuk membeli bahan baku bandeng segar dalam satu kali proses produksi yaitu sebesar Rp 744.953 (79,92\%).

Biaya Bahan Penolong. Bahan penolong dalam proses digunakan oleh produsen bandeng presto adalah bawang merah, bawang putih, jahe, kunyit, garam, penyedap, lengkuas, ketumbar, daun jeruk purut, daun salam, cabai, gas, kotak dan listrik. Pada Tabel 1 menunjukan bahwa biaya penolong yang di gunakam dalam proses produksi bandeng presto yaitu sebesar Rp 72.348 atau sebesar 7,77\%.

Biaya Tenaga Kerja. Tabel 1 menunjukkan bahwa biaya tenaga kerja yang dikeluarkan produsen bandeng presto sama, dalam satu kali produksi, baik dari responden awal sampai responden terakhir, biaya rata-rata tenaga kerja yang dikeluarkan untuk satu kali proses produksi adalah Rp 109.287/proses produksi $(11,72 \%)$.

\section{Biaya Tetap}

Biaya tetap adalah biaya yang besar kecilnya tidak dipengaruhi oleh volume produksi atau pengeluarannya bersifat konstan selama periode produksi. Yang termasuk biaya tetap dalam penelitian ini adalah biaya penyusutan alat. Biaya penyusutan alat, pada Tabel 1 dapat diketahui bahwa rata-rata biaya penyusutan alat pada bandeng presto untuk satu kali proses produksi adalah Rp $5.488(0,59 \%)$. 


\section{Produksi, Penerimaan, Total Biaya dan Pendapatan}

Tabel 2. Produksi, Penerimaan, Biaya dan Pendapatan Usaha Pengolahan Bandeng Presto di Kecamatan Palibelo, Tahun 2020

\begin{tabular}{rlr}
\hline No & \multicolumn{1}{c}{ Uraian } \\
& & Nilai \\
\hline 1 & Produksi (Kg) & 49,66 \\
2 & Harga (Rp/Kg) & 50.000 \\
3 & NilaiProduksi (Rp) & 2.483 .175 \\
4 & Total BiayaProduksi (Rp) & 932.076 \\
5 & Pendapatan (Rp) & 1.535 .424 \\
\hline
\end{tabular}

Sumber : Data Primer Diolah (2020)

Pada Tabel 2 rata-rata produksi yang diperoleh produsen yang memproduksi bandeng presto dalam satu kali proses produksi adalah sebanyak 49,66 kg dengan penerimaan sebesar Rp 2.483.175/proses produksi, sementara itu biaya produksi yang dikeluarkan untuk produksi bandeng presto yaitu Rp 932.076, sehingga diperoleh pendapatan sebesar Rp 1.535.424/proses produksi.

\section{NilaiTambah}

Besarnya tambahan nilai (manfaat) yang diperoleh sebagai akibat dari penggunaan sejumlah biaya dalam proses pengolahan bandeng presto. Hasil perhitungan nilai tambah pada usaha bandeng presto di Kecamatan Palibelo disajikan pada Tabel 3.

\section{Output, Input dan Harga Produk Bandeng Presto}

Bagian dari variabel ini mencakup : Produksi; Bahan baku; Tenaga kerja; Faktor konversi; Koefisien tenaga kerja; Harga output tata-rata; dan Upah rata-rata tenaga kerja.

Produksi, Bahan Baku dan Faktor Konversi. di sajikan pada Tabel 3. ratarata produksi yang diperoleh produsen yang memproduksi bandeng presto untuk satu kali proses produksi sebanyak 49,66 kg/proses produksi dengan harga output rata-rata sebesar Rp 50.000/proses produksi. Adapun rata-rata jumlah bahan baku yang digunakan untuk menghasilkan produksi tersebut adalah sebanyak $49.66 \mathrm{~kg}$, sehingga diperoleh faktor konversi sebesar 1.00. Nilai faktor konversi 1.00 berarti setiap $1 \mathrm{~kg}$ bahan baku dapat menghasilkan $1.00 \mathrm{~kg}$ produk bandeng presto.

Tenaga Kerja dan Koefisien Tenaga Kerja. rata-rata tenaga kerja yang digunakan dalam satu kali proses produksi bandeng presto yaitu sebanyak 2,07 HKO dengan koefisien tenaga kerja yaitu sebesar 0,04. Nilai koefisien tenaga kerja sebesar 0,04 pada bandeng presto berarti untuk mengolah $1 \mathrm{~kg}$ bahan baku hingga menjadi produk bandeng presto dibutuhkan tenaga kerja 0,04 HKO. 
Tabel 3. Nilai Tambah Usaha Pengolahan bandeng presto di Kecamatan Palibelo 2020

\begin{tabular}{|c|c|c|c|}
\hline \multirow[b]{2}{*}{ No. } & \multirow{2}{*}{ Variabel } & \multirow{2}{*}{ Formula } & \multirow{2}{*}{$\begin{array}{c}\text { Jenis Produk } \\
\text { Bandeng Presto }\end{array}$} \\
\hline & & & \\
\hline \multirow[t]{8}{*}{1} & Output, Input dan Harga & & \\
\hline & a. Produksi (Kg) & $\mathrm{a}$ & 49,66 \\
\hline & b. Bahan baku (Kg) & $b$ & 49,66 \\
\hline & c. Tenaga kerja (HKO) & $\mathrm{c}$ & 2,07 \\
\hline & d. Faktor konversi & $d=a / b$ & 1,00 \\
\hline & e. Koefisien tenaga kerja $(\mathrm{HKO} / \mathrm{Kg})$ & $\mathrm{e}=\mathrm{c} / \mathrm{b}$ & 0,04 \\
\hline & f. Harga output rata-rata $(\mathrm{Rp} / \mathrm{Kg})$ & $\mathrm{f}$ & 50.000 \\
\hline & g. Upah rata-rata tenaga kerja (Rp/HKO) & g & 109.287 \\
\hline \multirow[t]{10}{*}{2} & Penerimaan dan Keuntungan & & \\
\hline & h. Harga bahan baku (Rp/Kg) & h & 15.000 \\
\hline & i. Sumbangan input lain $(\mathrm{Rp} / \mathrm{Kg})$ & i & 13.781 \\
\hline & j. Nilai produksi $(\mathrm{Rp} / \mathrm{Kg})$ & $j=d x f$ & 50.000 \\
\hline & k1. Nilai tambah $(\mathrm{Rp} / \mathrm{Kg})$ & $\mathrm{k} 1=\mathrm{j}-\mathrm{i}-\mathrm{h}$ & 21.219 \\
\hline & k2. Rasio nilai tambah (\%) & $\mathrm{k} 2=(\mathrm{k} 1 / \mathrm{j}) \times 100 \%$ & 42,44 \\
\hline & 11. Imbalan tenaga kerja $(\mathrm{Rp} / \mathrm{Kg})$ & $11=\mathrm{e} \times \mathrm{g}$ & 4.557 \\
\hline & 12. Rasio bagian tenaga kerja (\%) & $12=(11 / \mathrm{k} 1) \times 100 \%$ & 21,47 \\
\hline & m1.Keuntungan $(\mathrm{Rp} / \mathrm{Kg})$ & $\mathrm{m} 1=\mathrm{k} 1-11$ & 16.662 \\
\hline & m2.Tingkat keuntungan $(\%)$ & $\mathrm{m} 2=(\mathrm{m} 1 / \mathrm{j}) \times 100 \%$ & 33,32 \\
\hline \multirow[t]{5}{*}{3} & Balas Jasa Pemilik Faktor-faktor Produksi & & \\
\hline & n. Margin Keuntungan & $n=j-h$ & 35.000 \\
\hline & n1. Pendapataan tenaga kerja (\%) & $\mathrm{n} 1=(11 / \mathrm{n}) \times 100 \%$ & 13,02 \\
\hline & n2. Sumbangan input lain (\%) & $\mathrm{n} 2=(\mathrm{i} / \mathrm{n}) \times 100 \%$ & 39,37 \\
\hline & n3. Keuntungan kegiatan prouksi (\%) & $\mathrm{n} 3=(\mathrm{m} 1 / \mathrm{n}) \times 100 \%$ & 47,61 \\
\hline
\end{tabular}

Sumber : Data Primer Diolah (2020)

\section{Penerimaan dan Keuntungan Produk Bandeng Presto}

Bagian dari variabel ini mencakup : Harga bahan baku; Sumbangan input lain; Nilai produksi; Nilai tambah; Rasio nilai tambah; Imbalan tenaga kerja; Rasio bagian tenaga kerja; Keuntungan; dan Tingkat keuntungan. Nilai-nilai setiap bagian pada variabel ini diperhitungkan untuk setiap kilogram bahan baku.

Harga Bahan Baku dan Sumbangan Input Lain.Disajikan pada tabel 4diketahui rata-rata bahan baku pada produk bandeng presto yaitu Rp 15.000/kg. Sebagaimana telah diuraikan sebelumnya, dalam proses produksi bandeng presto terdapat juga sumbangan input lain yaitu sumbangan bahan penolong. Pada Tabel 3. diketahui bahwa sumbangan bahan penolong pada bandeng presto adalah Rp 13.781/kg.

Nilai Produksi dan Nilai Tambah.disajikan pada Tabel 3. diketahui rata-rata nilai produksi yang diperoleh untuk setiap kilogram bahan baku pada bandeng presto adalah sebesar Rp 50.000/kg. Selanjutnya untuk menghitung nilai tambah pada 
bandeng presto dapat diperoleh dari selisih antara nilai produksi dengan harga bahan baku dan bahan penolong. Dari selisih tersebut diperoleh nilai tambah sebesar $\mathrm{Rp} 21.219 / \mathrm{kg}$ dengan rasio nilai tambah sebesar 42,44\%.

Imbalan Tenaga Kerja dan Rasio Imbalan Tenaga Kerja. Imbalan tenaga kerja diperoleh dari hasil kali antara koefisien tenaga kerja dengan upah rata-rata tenaga kerja. Imbalan tenaga kerja untuk produk bandeng presto adalah Rp 4.557/kg bahanbaku dengan rasio bagian tenaga kerja secara berurutan masing-masing sebesar $21,47 \%$.

Keuntungan dan Tingkat Keuntungan. Keuntungan untuk setiap kilogram bahan baku pada usaha bandeng presto diperoleh melalui selisih antara nilai tambah dengan imbalan tenaga kerja. Pada Tabel 3. keuntungan yang diperoleh pada produk bandeng presto adalah $\mathrm{Rp} 16.662 / \mathrm{kg}$ bahanbaku dengan tingkat keuntungan yaitu sebesar $33,32 \%$.

\section{Balas Jasa Pemilik Faktor-faktor Produksi pada Produk Bandeng Presto}

Bagian dari variabel ini mencakup : margin keuntungan, pendapatan tenaga kerja, sumbangan input lain (bahan penolong) dan keuntungan kegiatan produksi.

Disajikan pada Tabel 3. dapat diketahui bahwa pada produk bandeng presto, margin keuntungan sebesar Rp 35.000/proses produksi, balas jasa tenaga kerja sebesar $13,02 \%$ dan tingkat keuntungan kegiatan produksi sebesar $47.61 \%$.

\section{Kendala-kendala Usaha Pengolahan Bandeng Presto.}

Kendala-kendala tersebut menjadikan suatu usaha dapat terus berkembang karena adanya proses belajar menghadapi dan terus berusaha untuk meningkatkan produksi. Kendala usaha pengolahan bandeng presto disajikan pada Tabel 4 berikut.

Tabel 4. Kendala-kendala Usaha Pengolahan bandeng presto

\begin{tabular}{rlrr}
\hline No & \multicolumn{1}{c}{ JenisKendala } & Bandeng Presto & Persentasi (\%) \\
\hline 1 & Modal & 3 & 9,37 \\
2 & Bahan Baku & 20 & 62,50 \\
3 & TenagaKerja & - & - \\
4 & Pemasaran & 9 & 28,13 \\
\hline & Jumlah & 32 & 100,00 \\
\hline
\end{tabular}

Sumber : Data Primer Diolah 2020

Berdasarkan hasil penelitian pada usaha pengolahan bandeng presto di Kecamatan Palibelo Kabupaten Bima yang disajikan pada Tabel 4 diketahui bahwa terdapat beberapa kendala yaitu modal, bahan baku, dan pemasaran.

Disajikan pada Tabel 4, menunjukkan bahwa pengusaha bandeng presto memiliki kendala yang paling banyak yaitu bahan baku sebesar $62,50 \%$ dimana bahan baku yang dibutuhkan masih kurang karena adanya pengaruh cuaca. Kemudian pemasaran yaitu sebesar 28,13\% dimana para pelaku usaha sulit memasarkan produk dikarenakan oleh letak usaha yang kurang strategis. Adapun kendala lainnya adalah modal sebesar 9,37\% dimana pelaku usaha mempunyai keterbatasan modal untuk mengembangkan usaha. 


\section{KESIMPULAN DAN SARAN}

\section{Kesimpulan}

1. Proses pengolahan pada usaha bandeng presto terdiri dari 6 (enam) tahap yaitu pembersihan bahan baku, pembuatan bumbu, pelumuran bumbu, memasak bandeng, pendinginan, dan pengemasan.

2. Nilai tambah untuk bandeng presto adalah $\mathrm{Rp} 21.219 / \mathrm{kg}$ bahan baku dengan ratarata pendapatan sebesar Rp. 1.535.424/per daur usaha produksi, Rasio nilai tambah bandeng presto yaitu $42,44 \%$ artinya setiap Rp 100,- output akan menghasilkan nilai tambah yaitus ebesarRp 42,44.

3. Kendala-kendala yang dihadapi dalam usaha pengolahan bandeng presto yaitu kendala kesulitan mendapatkan bahan baku karena cuaca, kendala pemasaran karena letak usaha kurang strategis, dan keterbatasan modal.

\section{Saran}

Terbatas pada hasil penelitian dan kesimpulan yang telah diuraikan, maka dapat disarankan sebagai berikut :

1. Disarankan kepada pelaku usaha bandeng presto untuk membangun usaha ditempat yang strategis serta menggunakan media social dalam melakukan promosi produk agar pemasaran lebih mudah.

2. Diharapkan kepada pelaku usaha bandeng presto untuk melakukan mitra denganlembaga ekonomi keuangan seperti bank dan koperasi, agar mempermudah dalam medapatkan modal untuk pengembagan usahanya.

\section{DAFTAR PUSTAKA}

Dinas Kelautan dan Peikanan Provinsi Nusa Tenggara Barat. 2014. Mataram.

Dinas Kelautan dan Peikanan Kabupaten Bima 2015. Bima.

Nazir, Moh. 2014. Metode Penelitian. Ghalia Indonesia. Bogor.

Primyastanto, mimit, 2011. Fesibility Study Usaha Perikanan (sebagai aplikasi teori studi kelayakan usaha perikanan). Universitas Brawijaya Press (UB Press). Malang.

Sudiyono, 2004 Kerangka perhitungan nilai tambah metode Hayami

Soekartawi, 1995. Analisis Usaha Tani. Jakarta: UI-Press 